\title{
Hemispherectomy: Indications, Surgical Techniques, Complications, and Outcome
}

Alexandros G Brotis, MD, PhD*, lordanis Georgiadis, MD1, Kostas N. Fountas, MD, PhD*

Department of Neurosurgery, School of Medicine, University of Thessaly, Larisa, Greece

*Corresponding author: Alexandros G Brotis, Mavrogenous 65, Livadaki, Larissa / Greece, Tel: +306945296708; E-mail: alexgbrodis@yahoo.com

Received date: June 16, 2015; Accepted date: July 08, 2015; Published date: July 13, 2015

Copyright: $\odot 2015$ Brotis AG. This is an open-access article distributed under the terms of the Creative Commons Attribution License, which permits unrestricted use, distribution, and reproduction in any medium, provided the original author and source are credited.

\section{Introduction}

Surgical removal of a pathological, almost non-functional cerebral hemisphere is a relatively old concept in neurosurgery [1]. The evolution of hemispheric surgery from resection to disconnection techniques, along with a number of technological advances (light microscope, microneurosurgical tools, magnetic resonance imaging, neuro-navigation) resulted into significantly faster and less invasive procedures $[2,3]$. These improvements in association with prompt candidate selection resulted into further reduction of the procedureassociated mortality and morbidity [2-4]. Nowadays, hemispheric surgery techniques remain a viable treatment option for carefully selected, especially pediatric patients suffering from medically intractable, catastrophic epilepsy $[5,6]$.

The purpose of our current work is to provide a brief overview of the indications of the various surgical techniques, their potential complications and side effects, and their reported outcome rates.

\section{Historical Evolution}

Dandy reported the first hemispherectomy ever, for the treatment of a diffuse hemispheric glioma, in 1923 [1]. Fifteen years later, McKenzie was the first to describe hemispherectomy as a viable surgical strategy for treating medically intractable epilepsy [7]. Krynauw was the first to report his results from a series of pediatric patients, employing hemispherectomy for treating medically intractable epilepsy [8]. The first clinical series have reported seizurefree outcome rates after hemispherectomy to be as high as $70-80 \%$ $[9,10]$. Nevertheless, the occurrence of late complications, such as hydrocephalus and superficial hemosiderosis, decreased the initial enthusiasm and restricted its clinical applications $[11,12]$.

Since then, a number of modifications of the initially described surgical technique have been developed in order to minimize or to avoid these complications [12-15]. All the proposed modifications of the initial true anatomical hemispherectomy aimed towards less resection and more disconnection of the affected hemispheric structures from the healthy contralateral hemisphere [16]. Thus, the term anatomical hemispherectomy was replaced by the term hemispherotomy, which exactly denotes the disconnective nature of these procedures. The historical milestones in the evolution of the hemispherectomy surgical techniques are summarized in Table 1.

\section{Indications and Timing}

Hemispherectomy is indicated in patients with medically intractable epilepsy due to unilateral hemispheric lesions. Among them are included congenital (extensive, plurilobar cortical dysplasia, hemimegalencephaly, congenital extensive porencephaly, and SturgeWeber syndrome), and perinatal disorders (middle cerebral artery extensive infarcts, perinatal occlusion of the Sylvian aqueduct, Rasmussen encephalitis, West syndrome, and Lennox-Gastaut syndrome) [4]. The purpose of hemispherectomy is the elimination or the significant decrease of the patient's seizures and the facilitation of his/her psychomotor development. Four factors seem to play a major role in selecting the most appropriate time for surgery: the severity of the underlying epilepsy, the patient's neurological condition, the natural history of the underlying disease, and the patient's age [17]. In cases with catastrophic infantile epilepsy an early surgery is preferable. In other cases, surgery is postponed until hemiplegia and hemianopia have already commenced.

\section{Anesthetic Considerations}

The vast majority of surgical candidates are children or infants, so it is mandatory to co-operate with a specialized pediatric anesthesiologist. This age group is susceptible to hypothermia, electrolyte disturbances, and hypovolemic shock. The procedure is always performed under general endotracheal anesthesia and invasive cardiopulmonary monitoring (central venous line, intra-arterial line, transurethral catheter insertion). Warm air-blanket and intravenous fluids are essential for preventing perioperative hypothermia $[18,19]$. The induction of anesthesia is performed with pentothal and a mixture of nitrous oxide and isoflurane, supplemented by intravenous fentanyl for maintenance. The optimal PCO2 range is between $32-34 \mathrm{mmHg}$ in order to achieve maximum brain relaxation. A loading dose of steroids (dexamethasone) may be given intravenously in the morning of the surgery. Antibiotics, a gastro-protective agent, and anti-epileptic treatment are also indicated.

\section{Positioning and Surgical Preparation}

The patient's torso is placed in a semi-decubitus position, and the head is fixed with a three-point fixation device, rotated $45^{\circ}$, in order to achieve an almost horizontal position, with the affected hemisphere upwards. A foam-roll is placed under the ipsilateral shoulder. After meticulous skin prepping with antiseptic soap, the skin incision is infiltrated with a mixture of lidocaine, epinephrine and marcaine for minimizing blood loss during opening [18].

\section{Opening}

A skin incision should permit sufficient exposure of the working window. Critical landmarks are projected on the skin, while the utilization of a neuronavigational system could further facilitate the optimal placement of the craniotomy flap. It has to be emphasized, however, that the employment of neuronavigation cannot replace the usage of well known anatomical landmarks. It is of importance to minimize bleeding with the use of Raney clips and bipolar cautery, especially in children. The skin-flap is elevated and reflected 
anteriorly. The underlying temporalis fascia is reflected anteriorly, attached to the skin flap, so as to avoid trauma to the underlying facial nerve [18].

\begin{tabular}{|c|c|c|c|c|}
\hline Year & $\begin{array}{l}\text { Surger } \\
y\end{array}$ & $\begin{array}{l}\text { Indicatio } \\
\text { n }\end{array}$ & $\begin{array}{l}\text { Ptn } \\
\text { s }\end{array}$ & Comments \\
\hline $\begin{array}{l}\text { Dandy } \\
\text { (1928) [1] }\end{array}$ & $\mathrm{AH}$ & $\begin{array}{l}\text { Right- } \\
\text { sided } \\
\text { glioma }\end{array}$ & 5 & $\begin{array}{l}\text { Basal ganglia removal, ligation of } \\
\text { MCA and ACA at the carotid } \\
\text { bifurcation, } \\
\text { Hemisphere removed in fragments }\end{array}$ \\
\hline $\begin{array}{l}\text { Gardner } \\
\text { (1933) [20] }\end{array}$ & $\mathrm{AH}$ & Neoplasia & 3 & $\begin{array}{l}\text { Basal ganglia preservation improve } \\
\text { motor outcome }\end{array}$ \\
\hline $\begin{array}{l}\text { Mc Kenzie } \\
(1938)[7]\end{array}$ & $\mathrm{AH}$ & $\begin{array}{l}\text { Post- } \\
\text { traumatic } \\
\text { intractrabl } \\
\text { e seizures }\end{array}$ & 1 & En-block hemispheric removal \\
\hline $\begin{array}{l}\text { Krynauw } \\
(1950) \text { [8] }\end{array}$ & $\mathrm{AH}$ & $\begin{array}{l}\text { Infantile } \\
\text { hemiplegi } \\
\text { a }\end{array}$ & 12 & $\begin{array}{l}\text { Reduction in seizure frequency, } \\
\text { improvement in cognitive and } \\
\text { behavioral outcome }\end{array}$ \\
\hline $\begin{array}{l}\text { Falconer } \\
(1960) \text { [11] }\end{array}$ & $\mathrm{AH}$ & $\begin{array}{l}\text { Sturge - } \\
\text { Weber } \\
\text { Syndrome }\end{array}$ & 5 & $\begin{array}{l}\text { Reduction in seizure frequency, } \\
\text { improvement in behavioral } \\
\text { disorders, and worsening in } \\
\text { hemiplegia }\end{array}$ \\
\hline $\begin{array}{l}\text { Oppenheim } \\
\text { er and } \\
\text { Griffith } \\
\text { (1966) [9] }\end{array}$ & $\mathrm{AH}$ & $\begin{array}{l}\text { Infantile } \\
\text { hemiplegi } \\
\text { a }\end{array}$ & 18 & Described the SCH concept $(16.6 \%)$ \\
\hline $\begin{array}{l}\text { Wilson } \\
\text { (1968) [10] }\end{array}$ & $\mathrm{m}-\mathrm{AH}$ & $\begin{array}{l}\text { Infantile } \\
\text { hemiplegi } \\
\text { a }\end{array}$ & 50 & $\begin{array}{l}\text { SCH management with membrane } \\
\text { removal, lavage and shunting, and } \\
\text { foramen of Monroe obstruction with } \\
\text { a muscle plug }\end{array}$ \\
\hline $\begin{array}{l}\text { Rasmussen } \\
\text { (1983) [12] }\end{array}$ & $\mathrm{FH}$ & $\begin{array}{l}\text { Intractable } \\
\text { epilepsy }\end{array}$ & 57 & $\begin{array}{l}\mathrm{FH} \text { protects against } \mathrm{SCH} \text { at the } \\
\text { expense of seizure control }\end{array}$ \\
\hline $\begin{array}{l}\text { Delalante } \\
(1992 \text { and } \\
2007)[14]\end{array}$ & VPH & $\begin{array}{l}\text { Intractable } \\
\text { epilepsy }\end{array}$ & 83 & $\begin{array}{l}\text { VPH is a safe and effective } \\
\text { disconnection technique for } \\
\text { intractable epilepsy in children }\end{array}$ \\
\hline $\begin{array}{l}\text { Winston } \\
\text { (1992) [22] }\end{array}$ & $\mathrm{HC}$ & $\begin{array}{l}\text { Chronic } \\
\text { epilepsy }\end{array}$ & 11 & $\begin{array}{l}\text { HC outcome compares favorably } \\
\text { with that of more extensive surgical } \\
\text { procedures, yet is associated with } \\
\text { significantly less risk }\end{array}$ \\
\hline $\begin{array}{l}\text { Schramm } \\
\text { (1995) [15] }\end{array}$ & HD & $\begin{array}{l}\text { Intractable } \\
\text { epilepsy }\end{array}$ & 13 & $\begin{array}{l}\text { HD entails a smaller trepanation, } \\
\text { less operation time, and less blood } \\
\text { loss, it leaves more brain tissue, but } \\
\text { with equivalent seizure control as } \\
\text { compared with other functional } \\
\text { hemispherectomy techniques }\end{array}$ \\
\hline $\begin{array}{l}\text { Villemure } \\
\text { (1995) [13] }\end{array}$ & $\mathrm{PIH}$ & $\begin{array}{l}\text { Intractable } \\
\text { epilepsy }\end{array}$ & 11 & $\begin{array}{l}\mathrm{PIH} \text { is a minimally-aggressive } \\
\text { tractotomy with few complication }\end{array}$ \\
\hline $\begin{array}{l}\text { Schramm } \\
\text { (2001) [21] }\end{array}$ & TFH & $\begin{array}{l}\text { Intractable } \\
\text { epilepsy }\end{array}$ & 20 & $\begin{array}{l}\text { Method of choice in cases with } \\
\text { enlarged ventricles or perinatal } \\
\text { ischemic cysts and is not } \\
\text { recommended } \\
\text { hemimegalencephaly }\end{array}$ \\
\hline
\end{tabular}

Table 1: Milestones in hemispheric surgery (Ptns: number of patients, $\mathrm{AH}$ : anatomical hemispherectomy, SCH: superficial cerebral hemosiderosis, m-AH: modified anatomical hemispherectomy, $\mathrm{FH}$ : functional hemispherectomy, VPH: ventral parasagittal hemispherectomy, HC: hemicorticectomy, HD: hemispheric de- afferentation, PIH: peri-insular hemispherotomy, TFH: trans-sylvian functional hemispherectomy)

The initial craniotomy step is the placement of multiple burr holes according to the neuronavigation guidance, if this is available. The underlying dura is detached from the bone with a \#3 Penfield dissector. The adjacent burr holes are connected with a craniotome and the bone flap is carefully removed. Additional temporal bone is either drilled away or removed with a Leksel rongeur, so as to reach the anterior temporal area [18]

The dura is opened anteriorly, inferiorly, and posteriorly. The initial dural opening is made anteriorly and posteriorly with a \#15 blade. The rest of the dural opening is accomplished with Metzenbaum scissors using fine-toothed forceps to pick up the dura. Dural incision bleeding is controlled with hemostatic clips. The dural flaps, based toward the midline, are reflected. Particular attention needs to be paid to the fact that the dural flaps need to be maintained moistened through out the procedure [18].

\section{Anatomical Hemispherectomy}

Anatomical hemispherectomy (AH) is performed under the surgical microscope and achieved in three phases. Initially, the Sylvian fissure is opened [18]. The ipsilateral MCA is identified, dissected, clipped and divided lateral to the lenticulostriate branches of the basal ganglia. Similarly, the ipsilateral ACA is divided proximal to the origin of the calloso-marginal artery $[1,8,18]$. Care must be taken to avoid any catastrophic injuries to the contralateral vessels [18].

In the second step, the corpus callosum is properly identified and divided through an interhemispheric approach. The usage of a neuronavigator may be advantageous, especially in hemimegalencephaly cases, where the anatomical distortion could be easily misleading. Initially, all medial bridging cortical veins are identified, coagulated, and securely divided [18]. The callosotomy is performed using microdissection, coagulation, and aspiration techniques from the genu anteriorly to the splenium posteriorly [18]. A cottonoid is placed in the foramen of Monroe to protect the underlying choroid plexus and prevent the blood and debris entering the ventricular system [18]. Alternatively, it may be permanently plugged with a piece of muscle [10].

Finally, the fronto-basal white matter is divided through the anterior part of the lateral ventricle. The temporal stem is dissected and the ipsilateral anterior choroid and posterior communicating arteries are identified. The latter is clipped and divided at its P3 segment. The amygdala and the hippocampus are removed employing sub-pial dissection with special care on the preservation of the occulomotor nerve $[1,8,18]$. The obtaining of a preoperative magnetic resonance venography (MRV) could be beneficial for studying all bridging veins and for better and safer surgical corridor selection. The ipsilateral basal nuclei and thalamus may be left in situ for better motor outcome [20]. The exposed choroid plexus may be coagulated or left untouched, according to the surgeon's preference [1,18,20,21].

The method is characterized by high level of seizure control at an expense of increased morbidity risks.

\section{Cerebral Hemicorticectomy}

Winston developed a technique known as "cerebral corticectomy" in an effort to benefit from the success of $\mathrm{AH}$ in controlling intractable 
seizures but to avoid its associated complications. Nevertheless, this method did not gain popularity [22].

It has been described as a "de-gloving dissection" around the lateral ventricle, leaving thus a thin layer of white matter over the intact ependyma. The removed cortical gray matter was considered to be the source of all epileptogenic activity [22].

The hemisphere is exposed in the same manner as in $\mathrm{AH}$. The cerebral decortication includes a vertical cortical incision into the white matter, starting from the posterior Sylvian sulcus and continuing all over the parietal lobe. With a fan-like incision the frontal opercula is dissected away, undermining all neocortical structures. Next a large portion of the fronto-parietal cortex is dissected and removed. The cortex covering the temporal and occipital horns is removed. Finally, the remaining occipital cortex and corpus callosum are resected in a piecemeal fashion [22].

\section{Functional Hemispherectomy (Rasmussen's Modification)}

Functional hemispherectomy $(\mathrm{FH})$ is a four-step process [12,23]. The temporal lobe is removed with two cortical incisions, one on the superior temporal gyrus, running in parallel to the Sylvian fissure, and a second one placed on the dorsal temporal lobe, down to the temporal base, perpendicular to the first one. The posterior resection line is traced approximately $8 \mathrm{~cm}$ from the temporal pole. The hippocampus, the parahippocampal gyrus, the medial part of the uncus, and the lateral part of amygdala are removed with the ultrasonic aspirator after opening the temporal horn. The ipsilateral third cranial nerve should be protected.

The second step involves removal of the suprasylvian cortex by two parallel incisions perpendicular to the sylvian fissure, and providing access into the ipsilateral lateral ventricle $[12,18]$. This cortical block is $5-6 \mathrm{~cm}$ wide, and extends medially to the falx, containing the precentral and postcentral gyri, from the convexity, down to the Sylvian fissure. This step ends with transection of the corona radiata.

Completion of the transventricular parasagittal callosotomy is the main task of the third step. The remaining anterior and posterior callosal fiber tracts are disconnected from the ependymal surface toward the cingulate gyrus. The pericallosal artery constitutes the medial border of the resection, while working at the knee of the corpus callosum $[12,18]$.

Lastly, anterior and posterior disconnections of the frontal and parieto-occipital lobes take place $[12,18]$. The borders for the transsection of the corona radiata are the superior circular sulcus, the anterior cerebral artery, and the M1 segment of the middle cerebral artery. The posterior disconnection takes place after fully opening the Sylvian fissure and promptly elevating the parietal opercula. The disconnection line extends from the posterior part of the lateral ventricle opening, to the trigone of the temporal pole cavity $[12,18]$.

\section{Vertical Para-Sagittal hemispherotomy (Delalande Modification)}

The head is fixed in a neutral position, slightly elevated on the horizontal plane [14]. The skin incision is a linear transverse one, followed by a small parasagittal frontoparietal craniotomy, $3 \times 5 \mathrm{~cm}$ in size, with its anterior one-third located anterior to the coronal suture. The cortical window reaches the midline for easier access to the corpus callosum. Newer modifications suggest a laterally displaced frontoparietal window in order to avoid all the para-saggital veins [14].
Resection of a limited frontal cortex $(3 \times 2 \mathrm{~cm})$ facilitates entrance to the ipsilateral lateral ventricle and the foramen of Monro. The body and the splenium of the corpus callosum are resected, until the third ventricle is exposed. By severing the posterior column of the fornix at the level of the ventricular trigone, a posterior disconnection of the hippocampus is achieved [14].

A vertical incision lateral to the thalamus is carried out from the trigone to the most anterior part of the ventricle, guided by the choroid plexus of the temporal horn. Resections of the genu and the rostrum of the corpus callosum complete the callosotomy. The last step involves the resection of the posterior part of the gyrus rectus, which is possible through a straight incision anterolaterally through the caudate nucleus from the rectus gyrus to the anterior temporal horn [19]. Thus, all connections from the anterior temporal lobe, the amygdala, and the frontal lobe will be severed [14].

Vertical para-sagittal hemispherotomy (VPH) can be employed in cases of hemimegalencephaly and extensive multi-lobar cortical dysplasia, since it is based on reliable and readily identifiable anatomical landmarks. Finally, the surgeon can easily assess the completeness of the disconnection, intraoperatively. Its major drawback is the potential erroneous histopathological diagnosis, as the resected cortex is limited to the fronto-parietal area [14].

\section{Lateral Peri-insular Hemispherotomy (Villemure Modification)}

The PIH is a lateral disconnection procedure of the fronto-parietotemporal opercular cortices. A " $\pi$ "-shaped skin incision allows for a craniotomy over the insula, extending from the coronal suture to 3-4 $\mathrm{cm}$ behind the external auditory canal. Its lowest edge should be the bottom of the middle cranial fossa, all the way to the mid-convexity of the skull. The dural flap has a similar shape, and may be reflected either upwards or downwards [13].

The peri-insular approach is divided into three phases: the suprainsular, the infra-insular, and the insular phase. The subpial resection/ aspiration technique is employed during all the phases of this procedure [13].

In the supra-insular phase, the resection of the frontal and parietal opercula is carried out, leaving the underlying insular cortex completely exposed. Transection of the corona radiata is performed while opening the lateral ventricle from the frontal horn to the trigone. All tissue entering the callosum from the medial wall is transected, in order to perform a transventricular parasagittal callosotomy. Critical anatomical landmarks are the pericallosal arteries, the falx, and the cingulum. A partial de-afferentation of the hippocampus is subsequently accomplished by an incision through the fimbria and the fornix. Finally, the fronto-basal white matter is disconnected [13]. During the infra-insular phase a temporal lobotomy is performed (resection of the temporal operculum, transection of the temporal stem, and removal of the amygdala and the anterior hippocampus). At this stage, if the resection is maximal, the optic tract is visible. Finally, during the insular phase, the insula is resected in a piecemeal fashion $[13,19]$.

\section{Transsylvian Functional Hemispherotomy (Schramm Modification)}

The TFH constitutes a keyhole variant of hemispherotomy [21]. It is indicated for patients with atrophic hemispheres and enlarged 
ventricles, as in the case of perinatal ischemia or encephalomalacia. On the contrary, it should be avoided in patients with hemimegalencephaly, with an enlarged pathological hemisphere, aberrant anatomy, and abnormal vessels [17].

The skin incision, $10-12 \mathrm{~cm}$ in length, is slightly curved from anterior to the tragus up to the superior frontal area. The temporalis fascia is opened in the same way. The bone flap $(4 \times 5 \mathrm{~cm})$ is placed just above the Sylvian fissure with the usage of anatomical landmarks or neuronavigation. The anterior and inferior borders are formed by the limen insulae and the temporal operculum, respectively. The projection of the pulvinar represents the posterior border, and the anterior border is $5 \mathrm{~cm}$ anteriorly. The dural opening is performed by two diagonal incisions. The use of surgical microscope is mandatory [17].

The Sylvian fissure is widely opened to expose the circular sulcus and insula. All branches of the MCA are identified and properly exposed and skeletonized. The temporal horn is opened from the inferior circular sulcus, in order to perform an unco-amygdalohippocampectomy. The next step involves opening of the ipsilateral lateral ventricle in its entire length, which results in transection of the long fibers of the corona radiata. At this point, the insular cortex is entirely visible and may be safely removed. Finally, the mesial disconnection, progresses in three stages: the first stage involves disconnection of the fronto-basal white matter fibers, the second disconnection of the corpus callosum, and the third concerns disconnection of the occipital and parietal white matter fibers [17].

\section{Closure}

After completing the resective or disconnective part of the procedure, the surgical cavity is thoroughly irrigated in order to remove small blood clots and debris. Meticulous hemostasis is of paramount importance for avoiding any postoperative hematomas. Multiple dural tack-up sutures both at the periphery of the bone flap and at its center are used to prevent any epidural hematoma formation. The bone flap is secured back in its position by mini-plates and screws or by silk sutures. The surgical wound is closed in anatomical layers. An intraventricular and/or a subgaleal external drain may be occasionally used to remove any blood remnants from the cerebrospinal fluid and to prevent from any epidural collections, respectively [18].

\section{Postoperative Care}

The patient should be brought to the critical care unit for an uneventful extubation, close monitor of his/her vital functions and intensive neurological control. The nursing staff should be alerted for water and electrolyte disturbances in the ground of diabetes insipidus. In the case of significant intraoperative blood loss, volume and/or blood transfusion may be required. The anticonvulsant medication is continued in the postoperative setting [17]. In the following days intense physical therapy and rehabilitation assist in faster patient mobilization and optimal motor and language recovery [18].

\section{Complications}

The most serious intraoperative complications are bleeding and hypothermia. The former is more profound in patients with SturgeWeber syndrome or cortical dysplasia, and less common in those with Rasmussen encephalitis. Newer, less invasive surgical techniques have decreased the need for peri-operative blood transfusion to as low as
$8 \%[12,24]$. Bleeding can occur in the immediate postoperative period, as well. The main cause is the acute change of intracranial dynamics, leading to mechanical vascular distortion and tearing. Hemorrhage may be located even at areas remote to the surgical field [13].

Peri-operative bleeding can be minimized with a diligent surgical technique. Blood vessels should be gently handled though-out the whole procedure. The role of meticulous hemostasis with the usage of bipolar coagulation in bleeding-control cannot be overemphasized. The resection cavity should be copiously irrigated with saline until the fluid is crystal clear. When dry, a layer of hemostatic materials (Gelfoam, Surgicel, Tachoseal) should be applied to avoid any postoperative hematoma formation due to oozing.

Hemispherectomy remains the only currently employed epilepsy surgical procedure associated with significant perioperative mortality, ranging between $2-10 \%$ [18]. The causes of death are postoperative brain edema, tentorial herniation, acute onset postoperative hydrocephalus, and postoperative hemorrhage [25-31]. However, the most recent clinical series report significantly lower mortality rates, mainly due to the improved neurosurgical techniques, better neuroanesthesia, and better preoperative imaging modalities [32].

Superficial cerebral hemosiderosis $(\mathrm{SCH})$ is a complication that appears with a reported incidence as high as $30-50 \%$ after AH. It is manifested by progressive neurological deterioration after a mean time of eight years post-operatively [25]. The hemispherectomy cavity becomes lined with highly vascularised neo-membranes, as a result of chronic multiple microbleeding. The ventricles are filled-in with a brown, machine-oilfluid. It is associated with cerebral gliosis, ependymitis, and aqueductal stenosis, leading to hydrocephalus development $[25,26]$. It has to be mentioned that many clinical investigators consider this complication of historical significance, without any actual importance.

Obstructive hydrocephalus is among the most common complications with a reported incidence ranging from $2-26 \%$ in hemispheric surgery procedures. Hemimegalencephaly and multiple cortical dysplasias require more frequently a CSF shunting, postopertively [12]. Excision of the ipsilateral choroid plexus has been described in order to avoid this potential complication. Nowadays, CSF shunting at the same setting with the hemispherectomy procedure is widely advocated $[17,18,25]$.

Damage to major arteries and veins during surgery may lead to brain edema and ischemia. These conditions are potentially lethal as they raise the intracranial pressure and may lead to brain herniation [13]. Aseptic meningitis, third and sixth cranial nerve palsy, hyponatremia, and electrolyte dysbalances due to inappropriate antidiuretic hormone syndrome secretion have been described as less common complications of hemispheric surgery [24]. The early recognition of any procedure-associated complications, and their prompt management is of paramount importance for the good outcome of these patients.

\section{Outcome}

Complete abolition of seizures (Engel Class 1) has been reported to be as high as $43-90 \%$ (average 70\%), among patients undergoing hemispherotomy [13]. No data support that one hemispherotomy technique is superior to others, while the average reported seizure-free outcome is approximately $70 \%$ at the completion of the second postoperative year. Moreover, patients being treated with hemispherotomy had a comparable, if not better, seizure control 
outcome compared to those undergoing hemispherectomy $[12,14,17-19,24,33]$.

Postoperative neurological morbidity depends on the anatomic location of the underlying pathology and the patient's preoperative neurological status. Up to $84 \%$ of patients retain some form of effective walking after hemispherotomy [14,34]. It is important to note that about $50 \%$ of the patients lack fine finger motor function postoperatively $[14,17-19,24,33]$. Verbal skills show a higher chance of improvement compared to non-verbal skills [27]. Interestingly, this improvement is irrespective of the performance of a resective or a disconnective procedure [27]. The patient's age and the potential brain plasticity are important issues to be taken into consideration when considering language outcome [35]. Younger patients demonstrate better language outcomes after hemispherectomy/hemispherotomy. Generally, the cognitive improvement after hemispherectomy is assessed as moderate [32].

\section{Conclusion}

Hemispheric surgery remains a valid treatment option for patients suffering medically intractable, and usually catastrophic, epilepsy. The choice between hemispherectomy or hemispherotomy technique depends mainly on the underlying pathology, the patients age and his/her neurological status, as well as the surgeons experience. Hemispherotomy techniques offer the advantage of a less extensive and lengthy procedure, thus minimizing the chance of severe intraoperative bleeding. Hemispheric surgery procedures should be performed only in specialized centers, where there is abundance of expertise and adequate volume of cases, for optimal results.

\section{References}

1. Dandy WE (1923) Removal of right cerebral hemisphere for certain tumors with hemiplegia. JAMA 90: 823-825.

2. Obeid M, Wyllie E, Rahi AC, Mikati MA (2009) Approach to pediatric epilepsy surgery: State of the art, Part I: General principles and presurgical workup. Eur J Paediatr Neurol 13: 102-114.

3. Obeid M, Wyllie E, Rahi AC, Mikati MA (2009) Approach to pediatric epilepsy surgery: State of the art, Part II: Approach to specific epilepsy syndromes and etiologies. Eur J Paediatr Neurol 13: 115-127.

4. Tatum WO, Kaplan PW, Jallon P (2009) Hemspherectomy. In: Epilepsy A to Z: A Concise Encyclopedia (2nd edn) New York: Demos medical publishing, New York.

5. Spencer S, Huh L (2008) Outcomes of epilepsy surgery in adults and children. Lancet Neurol 7: 525-537.

6. Wen HT, Rhoton AL Jr, Marino R Jr (2004) Anatomical landmarks for hemispherotomy and their clinical application. J Neurosurg 101: 747-755.

7. McKenzie KG (1938) The present status of a patient who had the right cerebral hemisphere removed. JAMA 111:168.

8. Krynauw RA (1950) Infantile hemiplegia treated by removing one cerebral hemisphere. J Neurol Neurosurg Psychiatry 13: 243-267.

9. Oppenheimer DR, Griffith HB (1966) Persistent intracranial bleeding as a complication of hemispherectomy. J Neurol Neurosurg Psychiatry 29: 229-240.

10. Wilson PJ (1970) Cerebral hemispherectomy for infantile hemiplegia. A report of 50 cases. Brain 93: 147-180.

11. Falconer MA, Wilson PJ (1969) Complications related to delayed hemorrhage after hemispherectomy. J Neurosurg 30: 413-426.

12. Rasmussen T (1983) Hemispherectomy for seizures revisited. Can J Neurol Sci 10: 71-78.
13. Villemure JG, Mascott CR (1995) Peri-insular hemispherotomy: surgical principles and anatomy. Neurosurgery 37: 975-981.

14. Delalande O, Bulteau C, Dellatolas G, Fohlen M, Jalin C, et al. (2007) Vertical parasagittal hemispherotomy: surgical procedures and clinical long-term outcomes in a population of 83 children. Neurosurgery 60 : ONS19-32.

15. Schramm J, Behrens E, Entzian W (1995) Hemispherical deafferentation: an alternative to functional hemispherectomy. Neurosurgery 36: 509-515.

16. Schuele SU, Lüders HO (2008) Intractable epilepsy: management and therapeutic alternatives. Lancet Neurol 7: 514-524.

17. Binder DK, Schramm J (2006) Transsylvian functional hemispherectomy. Childs Nerv Syst 22: 960-966.

18. Fountas KN, Smith JR, Robinson JS, Tamburrini G, Pietrini D, et al. (2006) Anatomical hemispherectomy. Childs Nerv Syst 22: 982-991.

19. De Ribaupierre S, Delalande O (2008) Hemispherotomy and other disconnective techniques. Neurosurg Focus 25: E14.

20. Gardner WJ, Karnosh LJ, Mcclure CC Jr, Gardner AK (1955) Residual function following hemispherectomy for tumour and for infantile hemiplegia. Brain 78: 487-502.

21. Schramm J, Kral T, Clusmann H (2001) Transsylvian keyhole functional hemispherectomy. Neurosurgery 49: 891-900.

22. Winston KR, Welch K, Adler JR, Erba G (1992) Cerebral hemicorticectomy for epilepsy. J Neurosurg 77: 889-895.

23. Schramm J (2008) Functional hemispherectomy. In: Neurosurgical operative atlas: Functional neurosurgery. Edited by Starr PA, Barbaro NM, Larson PS. (2nd edn) Thieme medical publishers, New York.

24. Basheer SN, Connolly MB, Lautzenhiser A, Sherman EM, Hendson G, et al. (2007) Hemispheric surgery in children with refractory epilepsy: seizure outcome, complications, and adaptive function. Epilepsia 48: 133-140.

25. Shorvon SD (2010) The surgical therapy of epilepsy: Handbook of Epilepsy Treatment (3rd edn) Wiley-Blackwell, London.

26. Peacock WJ (1995) Hemispherectomy for the treatment of intractable seizures in childhood. Neurosurg Clin N Am 6: 549-563.

27. Di Rocco C, Battaglia D, Pietrini D, Piastra M, Massimi L (2006) Hemimegalencephaly: clinical implications and surgical treatment. Childs Nerv Syst 22: 852-866.

28. Cabieses F, Jeri R, Landa R (1957) Fatal brain-stem shift following hemispherectomy. J Neurosurg 14: 74-91.

29. Carmichael EA (1966) The current status of hemispherectomy for infantile hemiplegia. Clin Proc Child Hosp Dist Columbia 22: 285-293.

30. Wroe S, Richens A, Compston A (1986) Bilateral ballistic movements occurring as a late complication of hemispherectomy and responding to sulpiride. J Neurol 233: 315-316.

31. Wester K, Hugdahl K, Asbjørnsen A (1991) Dichotic listening during forced-attention in a patient with left hemispherectomy. Percept Mot Skills 72: 151-159.

32. Carson BS (2008) Hemispherectomy: Principles and practice of pediatric neurosurgery. Edited by Albright AL, Adelson PD, Pollack IF. (2nd edn) Thieme medical publishers, New York.

33. Daniel RT, Villemure JG (2003) Peri-insular hemispherotomy: potential pitfalls and avoidance of complications. Stereotact Funct Neurosurg 80: 22-27.

34. Maehara T, Shimizu H, Kawai K, Shigetomo R, Tamagawa K, et al. (2002) Postoperative development of children after hemispherotomy. Brain Dev 24: $155-160$.

35. Hertz-Pannier L, Chiron C, Jambaqué I, Renaux-Kieffer V, Van de Moortele PF, et al. (2002) Late plasticity for language in a child's nondominant hemisphere: a pre- and post-surgery fMRI study. Brain 125: 361-372. 